\title{
Telemedicine Healthcare Service Adoption Barriers in Rural Bangladesh
}

\author{
Khondker Mohammad Zobair \\ Department of Business Strategy and Innovation \\ Griffith University \\ zobair@hotmail.com
}

\section{Louis Sanzogni}

Department of Business Strategy and Innovation

Griffith University

\section{Kuldeep Sandhu}

Department of Business Strategy and Innovation Griffith University

\section{Abstract}

This article investigates potential barriers to telemedicine adoption in centres hosted by rural public hospitals in Bangladesh. Little is known of the barriers related to telemedicine adoption in this context. Analysis of data collected from rural telemedicine patients identified seven broad categories of barriers: lack of organisational effectiveness, information and communication technology infrastructure, quality of care, allocation of resources, health staff motivation, patient satisfaction and trustworthiness. Their significance is explored. This research is based on the quantitative analysis of a data set of 500 telemedicine patients, from rural areas in Bangladesh. A conceptual model showing the interaction of pre-determined classes of barriers was established and hypotheses set up and tested using partial least squares structural equation modelling. Exemplary barriers to telemedicine adoption were identified and confirmed $(p<.01)$ namely, lack of organisational effectiveness, health staff motivation, patient satisfaction, and trustworthiness collectively explaining $62 \%$ of the variance in barriers to adoption and providing for the first-time empirical support of their existence. These barriers offer considerable resistance to the adoption and maintenance of current telemedicine projects in rural Bangladesh. Further, lack of information and communication technology infrastructure, allocation of resources and quality of care are indirect barriers affecting successful deployment of telemedicine in rural settings. These findings illuminate adoption impediments faced by existing telemedicine projects and institutionalise favourable policy guidelines to improve Bangladesh's and similar emerging economies' healthcare industries. Policy interventions and recommendations are provided, including current research limitations leading to opportunities for future research.

Keywords: adoption, barriers, ICT, PLS-SEM, rural and remote areas, telemedicine

\section{Introduction}

Telemedicine can provide improved and more flexible primary healthcare support to rural and underprivileged people in developing countries. Its primary objective is to improve healthcare services to geographically disadvantaged and medically underserved populations by providing high-quality care at reduced cost, offering greater convenience (LeRouge \& Garfield, 2013). Though there is high interest in telemedicine worldwide, the implementation rate is lagging (Bullock, Vehe, Zhang, \& Correll, 2017) due to organisational, infrastructural, 
strategic, technological, financial, ethical, legal, and human resources barriers (LeRouge \& Garfield, 2013). This article investigates potential barriers impeding the adoption of telemedicine healthcare services in centres hosted by rural Bangladesh's public hospitals serving medically disadvantaged rural populations.

Bangladesh's healthcare system is highly pluralistic (Ahmed et al., 2014), consisting of public, private and non-government organisations (NGOs), and healthcare systems aided by international donor agencies (Hamid, Ahsan, Begum, \& Asif, 2015). Many urban and rural communities depend on non-institutional health facilities served by private health practitioners (Paul, 1983). Telemedicine must be integrated into healthcare industries to better manage and coordinate Bangladesh's healthcare systems (Gibson et al., 2011). Telemedicine could hold substantial promise (Mars, 2013) to achieve Bangladesh's political health agenda (Nissen \& Lindhardt, 2017), including facilitating better access to health services for rural communities (Gibson et al., 2011).

\subsection{Research Rationale}

There is growing consensus that telemedicine is a solution to delivering affordable healthcare support. Telemedicine can improve health access, service quality, clinician and patient satisfaction (Zhang, Luo, Nie, \& Zhang, 2017), and can link rural and remote communities with distant care reducing travel time and cost (Jang-Jaccard, Nepal, Alem, \& Li, 2014). Due to a significant shortage of highly qualified health professionals, there has been growing demand for ICT-based health services in low and middle income countries (Ahmed et al., 2014). Telemedicine holds much promise (Mars, 2013). However, awareness among stakeholders as well as issues of privacy, confidentiality, defensive medical practices and fears (Parimbelli et al., 2018), unfamiliarity with required skills and knowledge, and difficulties handling ICT applications (Koivunen \& Saranto, 2018) form complex barriers to broader telemedicine adoption in Bangladesh clinical practices (Parimbelli et al., 2018). These barriers give impetus to this research.

\subsection{Telemedicine in Bangladesh}

The government of Bangladesh is aggressively introducing telemedicine healthcare services to ensure national success in healthcare intervention. e-Health services were initiated in 1998 under the Ministry of Health and Family Welfare (MOHFW) to enhance public healthcare systems (M. R. Hoque \& Bao, 2015). Telemedicine was established in 1999 and the Bangladesh Telemedicine Association in 2001 but due to insufficient attention, telemedicine has remained beyond the reach of much of the disadvantaged population (Nessa, Ameen, Ullah, \& Kwak, 2008). In 2010, telemedicine was adopted in public hospitals under MOHFW in partial fulfilment of the 2021 Digital Bangladesh vision. There are 84 active telemedicine centres in 57 of Bangladesh's 488 Upazila (i.e., subdistrict) hospitals. The integration of 27 specialised, district-level and medical college hospitals that provide telemedicine support to existing rural telemedicine centres is considered a significant shift in Bangladesh's public healthcare sector. A central database system has been established to store data from health facilities, including data from all public health professionals (Ahmed et al., 2014). Despite growing demand for telemedicine, the adoption rate is slow and below expectations (Menachemi, Burke, \& Ayers, 2004). Nevertheless, while telemedicine projects in Bangladesh have faced challenges since 1999 (Nessa et al., 2008), some have become fully operational, providing large-scale services and benefits meriting its continued consideration (Williams, Bhatti, Alam, \& Nikolian, 2018), 
and giving strength to patients' attitudes, awareness, and understandings of the viability of telemedicine projects.

Some empirical studies (Ahmed et al., 2014; R. Hoque \& Sorwar, 2017), have investigated the status of e-Health and m-Health initiatives in Bangladesh. For example, government and nongovernment sectors (i.e., profit, non-profit and NGOs) (M. R. Hoque, Karim, \& Amin, 2015), contribute to e-Health and $\mathrm{m}$-Health services but are embryonic and need substantial research to overcome the challenges of successful adoption (M. R. Hoque, 2016). In existing Bangladeshrelated literature that focuses on e-Health and m-Health adoption issues, no studies were found on telemedicine adoption, nor have correlations been identified between providerreported barriers and telemedicine adoption. This represents a considerable knowledge gap duly addressed by this study.

\section{Review of the Literature (Hypotheses and Conceptual Model)}

The reviewed literature suggests that ICT-based healthcare research is varied and influenced by researchers' perspectives (Vishwanath \& Scamurra, 2007). No conceptual or theoretical frameworks concerning the relationships between telemedicine barriers and adoption were found. Robust prior studies in telemedicine, e-Health, telehealth, and m-Health (Alaboudi et al., 2016; Bigna, Noubiap, Plottel, Kouanfack, \& Koulla-Shiro, 2014; Boonstra \& Broekhuis, 2010; Bullock et al., 2017; Cajita, Hodgson, Lam, Yoo, \& Han, 2018; De Bustos, Moulin, \& Audebert, 2009; Faber, van Geenhuizen, \& de Reuver, 2017; Freed et al., 2018; Gravel, Légaré, \& Graham, 2006; Jang-Jaccard et al., 2014; Johnson, 2001; Leaming, 2007; LeRouge \& Garfield, 2013; Lin, Lin, \& Roan, 2012; Lohmann, Muula, Houlfort, \& De Allegri, 2018; Modi, Portney, Hollenbeck, \& Ellimoottil, 2018; Moffatt \& Eley, 2011; Ramtohul, 2015; Rogove, McArthur, Demaerschalk, \& Vespa, 2012; Scott Kruse et al., 2018; Scott \& Mars, 2013; Van Dyk, 2014; Whitten, Holtz, Meyer, \& Nazione, 2009) were used to develop and test the hypotheses regarded as mutually exclusive and exhaustive when considered from a model parsimony perspective. These seven broad categories of barriers are encapsulated in the study's conceptual model (see Figure 1).

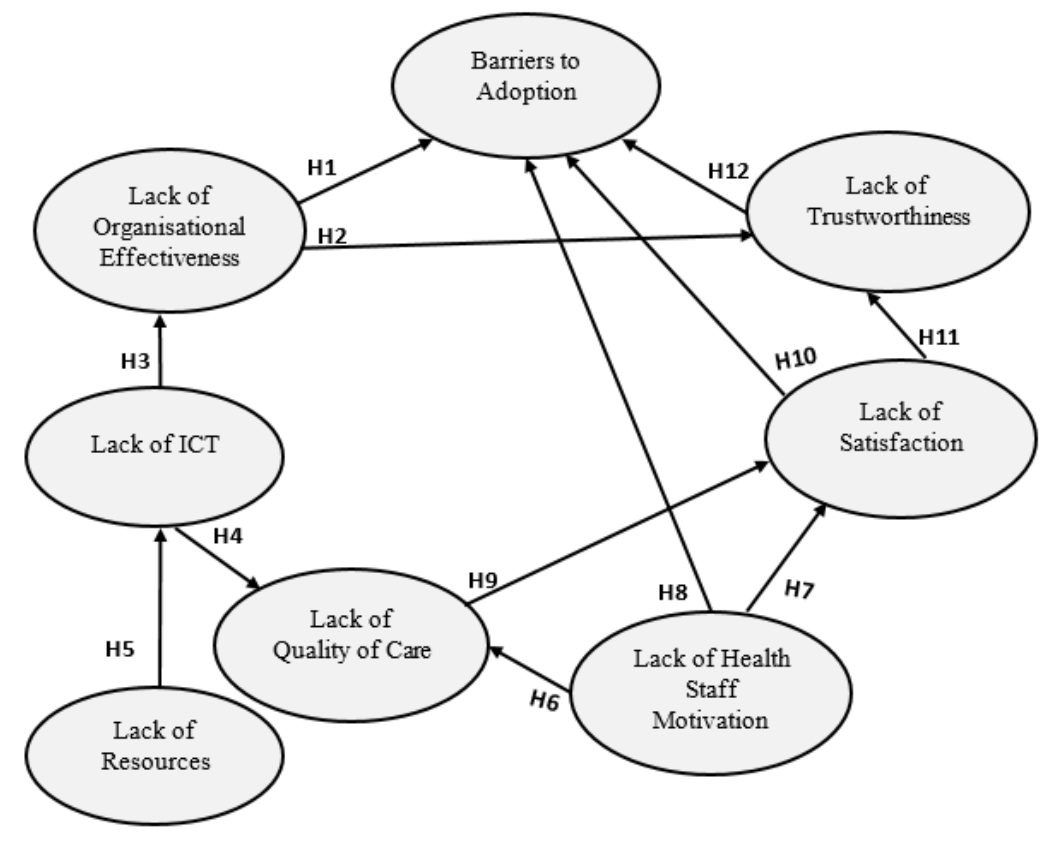

Figure 1. Conceptual model. 


\subsection{Organisational Barriers}

Whittaker, Aufdenkamp, and Tinley (2009) and Kifle, Mbarika, Tsuma, Wilkerson, and Tan (2008) have documented potential users, organisational infrastructure, and policy as significant barriers to telemedicine adoption. Lack of organisational effectiveness is also considered to be a significant telemedicine adoption barrier (Evans, 2015). Van Dyk (2014) reported that policy, change management, economic feasibility, perception, user-friendliness, and governance, have influence over the adoption of telehealth (i.e., telemedicine) services. Legislation, organisational infrastructure, societal factors (Boonstra \& Broekhuis, 2010; Van Dyk, 2014) and strategic planning (Modi et al., 2018; Scott \& Mars, 2013), have also been reported to have influence on e-Health (i.e., telemedicine) adoption.

Bangladesh's healthcare industries have found it difficult to enhance service quality and improve accessibility (S. Akter, M. Upal, \& U. Hani, 2008), partly because of the low rate of telemedicine deployment in rural settings. Studies reveal that providing high-quality care (Williams et al., 2018), leadership engagement (Ross, Stevenson, Lau, \& Murray, 2016), and regulations and health guidelines are indispensable for building health seekers' trust (Oak, 2007). Uncertainty about rules and clinical guidelines are considered dominant barriers (Martin, Probst, Shah, Chen, \& Garr, 2012) that may influence organisational trustworthiness and many e-Health projects fail because of inadequate regulatory policy integration (Gagnon et al., 2009). De Bustos et al. (2009) argued that success in e-Health adoption is possible only if the underpinning barriers can be identified and overcome. Therefore, the following hypotheses are proposed:

Hypothesis 1: Organisational effectiveness influences telemedicine adoption success.

Hypothesis 2: Organisational effectiveness influences patient' trustworthiness in telemedicine usage.

\subsection{Technological Barriers}

Telemedicine is a technology-based healthcare system that can contribute to better health management by integrating ICT, clinics and the internet to provide teleconsultation between clinicians and patients (Kiberu, Mars, \& Scott, 2017). Rural communities in developing countries are deprived of quality health services because of poor ICT infrastructure (Hossain, Yokota, Sultana, \& Ahmed, 2018). However, in Bangladesh the ICT sector has grown considerably in recent years, demonstrating an outstanding dominating position. Most of the population (99\%) have access to mobile networks that cover $92 \%$ of the geographical area, and $97 \%$ of households have at least one mobile phone (Ahmed et al., 2014). Islam et al. (2017) reported that $73.9 \%$ of participants share health information through social media, demonstrating a sophisticated level of engagement with ICT-based health to make informed health decisions. In the public health sector, ICT resources remain inadequate and reliability issues make it a potential technological barrier (Van Dyk, 2014). Many telemedicine technologies appear unsuccessful because they have a significant low effect on healthcare practices and often disregard interdependencies between technology, human characteristics, and socioeconomic circumstances (van Gemert-Pijnen et al., 2011).

Hasan (2012) reported that in Bangladesh, internet access and power supply are not sufficiently reliable to successfully adopt telemedicine. This is supported by M. R. Hoque, Mazmum, and Bao (2014) who mentioned that in Bangladesh, Internet access and power supply are not sufficiently reliable to adopt successful telemedicine services. These are critical barriers to a secure ICT infrastructure (Lewis, Synowiec, Lagomarsino, \& Schweitzer, 2012), 
and they can impede quality of care, life and productivity (Zanaboni \& Wootton, 2016). Therefore, the following hypotheses are proposed:

Hypothesis 3: ICT infrastructure influences organisational effectiveness.

Hypothesis 4: ICT infrastructure influences quality of care.

\subsection{Resource Allocation Barriers}

As a developing country, Bangladesh lacks the resources to deploy telemedicine (Khan, Hossain, Hasan, \& Clement, 2012). Kiberu et al. (2017) found that equipment costs, and insufficient human resources allocations are considered to be potential resources barriers to telemedicine adoption. The literature further reports that change resistance among patients and health staff, human resources, uncertainty of ownership, ICT skills, policymaking, leadership and coordination, monitoring and evaluation, cultural and language barriers (Fanta, Pretorius, \& Erasmus, 2015), service delivery issues (Hossain et al., 2018), hardware access (Boonstra \& Broekhuis, 2010), financial resources allocation (E. Miller, 2010), resources allocation (Boonstra \& Broekhuis, 2010), legal and ethical factors (Anderson, 2007), and appropriate equipment (Kruse et al., 2018) are dominant resource barriers to telemedicine adoption. Weinstein et al. (2014) mentioned that the cost, allocation of funding for equipment and the recruitment of physicians are considered the dominant barriers to telemedicine adoption. Likewise, E. Miller (2010) found that financial constraints, resources allocations, and inadequate supplies are dominant barriers to telemedicine adoption. Therefore, the following hypothesis is proposed:

Hypothesis 5: Allocation of resources influences the adequacy of ICT infrastructure.

\subsection{Health Staff Motivation Barriers}

Health staff motivation is defined as the degree to which a staff member is willing to perform assigned tasks to attain organisational goals (Franco, Bennett, \& Kanfer, 2002) and is a vital issue facing many developing countries (Jayasuriya, Jayasinghe, \& Wang, 2014). Financial incentives could be a crucial determinant of staff motivation because health services are entirely labour intensive (Franco et al., 2002). If health workers do not perceive personal benefits from telemedicine, they will be unmotivated to change their working habits (Vishwanath \& Scamurra, 2007). When health staff are rewarded with financial incentives based on job performance, their motivation increases, fostering e-Health implementation (Boonstra \& Broekhuis, 2010) and the provision of better health services that contribute to patient satisfaction in telemedicine services (Ross et al., 2016).

Lack of clear benefits, incentives and support for physicians, poor patient-clinician communication, marketplace competition and privacy legislation (Boonstra \& Broekhuis, 2010), shortcomings in facilities (Jayasuriya et al., 2014), a strong sense of mission and observable organisational effectiveness are considered critical issues tied to staff motivation (E. Miller, 2010). Interpersonal relationships remain cornerstones of health staff motivation, provided they facilitate understanding and improve the exchange of health information between clinicians and patients (Weiner \& Biondich, 2006). This translates into detailed health histories and better health treatment plans and outcomes (Shaarani, Taleb, \& Antoun, 2017). Patients expect high-quality services at an affordable cost and providing poor-quality service (Martin et al., 2012) encourages patients to bypass local health providers and travel to urban hospitals (Nesbitt, Marcin, Martha, \& Cole, 2005). Financial incentives could lead to quality 
improvement, intensifying telemedicine service adoption (R. H. Miller \& Sim, 2004). Therefore, the following hypotheses are proposed:

Hypothesis 6: Health staff motivation influences quality of care.

Hypothesis 7: Health staff motivation influences patient satisfaction.

Hypothesis 8: Health staff motivation influences telemedicine adoption success.

\subsection{Quality of Care Barriers}

Growing demands, spiralling costs, and inadequate and inconsistent service quality and delivery are risking ICT-supported healthcare systems (Lluch, 2011). The quality level of Bangladesh's healthcare services is a significant concern (Chandler, Chonya, Mtei, Reyburn, \& Whitty, 2009) and patient satisfaction regarding quality of care is consistently neglected (M. S. Akter, M. Upal, \& U. Hani, 2008). A recent study (de la Torre Díez, Alonso, Hamrioui, LópezCoronado, \& Cruz, 2018) claimed that in telemedicine provision, the quality of both service and experience is mandatory to maintain patient health. Uncoordinated monitoring, inconsistent service quality, insufficient privacy and confidentiality, and poor coordination can be potential barriers to patient satisfaction in telemedicine services (Lluch, 2011). Physician-patient relationship interference is the most cited barrier to telemedicine healthcare service adoption (Boonstra \& Broekhuis, 2010). Therefore, the following hypothesis is proposed:

Hypothesis 9: Quality of care influences patient satisfaction.

\subsection{Patient Satisfaction Barriers}

Health client satisfaction is critical to healthcare quality assessment and establishes organisational loyalty - a core issue in the healthcare industry's survival (Elbeck, 1987). Hage, Roo, van Offenbeek, and Boonstra (2013) revealed that telemedicine services that do not meet demand and have poor availability or accessibility lead to significant patient distrust and service dissatisfaction. de la Torre Díez et al. (2018) described the service quality perceived by telemedicine patients as "quality of service experience", while Martin et al. (2012) claimed that patients expect high-quality services from providers. Conversely, poor-quality services contribute to patient dissatisfaction and untrustworthiness. Medical malpractice, unclear laws about telemedicine practices and inconsistent virtual medical devices at rural hospitals are dominant barriers continuing to plague telemedicine health provision (Boonstra \& Broekhuis, 2010). Studies report that patients may travel to other providers (Call et al., 2015) if telemedicine is unable to satisfy them by improving access, facilitating patient education and engagement, and promoting clinical care (Mathieson, Leafman, \& Horton, 2017).

Therefore, the following hypotheses are proposed:

Hypothesis 10: Patient satisfaction influences telemedicine adoption success.

Hypothesis 11: Patient satisfaction influences trustworthiness in telemedicine usage.

\subsection{Patient Trustworthiness Barriers}

Trustworthiness in telemedicine plays a critical role in forming patients' confidence and ensuring their intentions to reuse the system (Akter, D'Ambra, \& Ray, 2011). Trustworthiness incorporates three characteristics namely, ability, benevolence, and integrity (Mayer \& Davis, 1999), and is critical in forming patient confidence and continuing intentions to reuse the system (Akter et al., 2011). Inadequate monitoring, lack of usefulness (Vishwanath \& 
Scamurra, 2007) and lack of patient privacy, confidentiality and data security (Chang, 2015), adds to users' distrust about telemedicine service delivery. Further significant barriers are a lack of management support, security standards, and clear patient benefits (Vishwanath \& Scamurra, 2007). Therefore, the following hypothesis is proposed:

Hypothesis 12: Patients' trustworthiness in telemedicine usage influences telemedicine adoption success.

\section{Research Methodology}

\subsection{Research Instrument Development}

Initially a conceptual model with key constructs, corresponding indicators, and scales was synthesised from existing, established research (Lankton \& Wilson, 2007; Venkatesh, Morris, Davis, \& Davis, 2003), and extended/adapted to fit the proposed study (Padovani \& Carvalho, 2016; Webster \& Watson, 2002). It was then further refined through data collected from participant observation, group discussions, and in-depth interviews before finalising the constructs, indicators, and scales, leading to the establishment of a survey instrument to collect data to empirically validate the hypotheses and the model. Partial least squares structural equation modelling (PLS-SEM; SmartPLS v.3.2.7) (Marzagão \& Carvalho, 2016) was used for data analysis. The PLS algorithm tool tested scales reliability, and a bootstrapping algorithm technique tested the hypothesis and structural model (Zhang et al., 2017).

A seven-point Likert scale was used (i.e., 1 = very strongly disagree to 7 = very strongly agree) as recommended (Lankton \& Wilson, 2007) for healthcare surveys. Most scales used in this study were drawn from existing literature and were modified (Lankton \& Wilson, 2007) to develop and validate appropriate scales for the present research. Two management information systems experts examined the survey questionnaire for logical consistency, contextual relevance, terminology, and measurement content clarity (Zhang et al., 2017). A focus group of 15 Bangladeshi PhD students were invited to evaluate the questionnaire (Venkatesh et al., 2003) due to their academic skills, research experience, and knowledge about telemedicine services in rural Bangladesh. The feedback from the evaluation was used to rectify/refine the questionnaire. In addition, the questionnaire (constructs, indicators, and scales) was tested for content validity and reliability in a pilot study involving $n=25$ telemedicine users representing $5 \%$ of the target sample (J. W. Cresswell \& Clark, 2011). An iterative rectification process was performed until the questionnaire reached an acceptable range of criterion validity.

The questionnaire was initially developed in English, translated into Bangla, retranslated into English and adjusted so that both versions were comparable (Akter et al., 2011). The survey questionnaires were distributed including informed consent forms to respondents who agreed to participate in the survey. The accompanying documentation reinforced that participation was voluntary and they could withdraw their involvement anytime.

\subsection{Sample and Data Collection}

The survey commenced after approval from the Directorate of General Health Services, MOHFW, as well as ethical clearance from the university. A pilot test was conducted according to J. W. Cresswell and Clark (2011) using a random selection of about $5 \%$ of the intended survey sample from three different study regions. High response rates were obtained. Four university graduates were recruited to execute the survey. They were briefed 
on the study's intent and instructed to read each survey question precisely, practice neutral tones, document participants' answers accurately, and be non-judgemental (Neuman, 2014). The data collection occurred from mid-January to mid-March 2017. A significant response rate $(98.40 \%)$ was obtained and considered adequate to fulfil the research purpose.

Data were obtained from rural telemedicine patients from three subdistricts in Bangladesh. Each group was statistically representative of the telemedicine population, relying on commonalities in telemedicine infrastructure and comparable clinical methods across all Bangladesh telemedicine centres. The telemedicine service facilities (i.e., operation standards) provided by the government were equal for all existing centres. Costs, homogeneity, and a high concentration of the telemedicine population were also considered during subdistrict selection.

A multistage random sampling method was deemed suitable for this study and is considered appropriate for ICT-based medical research. Burt and Sisk (2005) applied this sampling technique for electronic health records in e-Health research. Probability random sampling techniques are ideal for achieving high accuracy, efficiency, and consistency in research outcomes (Neuman, 2014).

The telemedicine population was defined as those who had experienced telemedicine at least once in any rural telemedicine centre during the past 12 months. Three districts where telemedicine centres existed were randomly selected. One district from the north and two from the south, east and west regions of Bangladesh were excluded due to resource and time constraints, and reduced patient concentrations during the data collection period. The randomly selected districts were Pubna, Khulna and Satkhira from which three Upazila telemedicine centres were randomly selected. From these, a total of 500 samples were randomly designated for data collection, with each patient having an equal chance of being selected (Akter et al., 2011). The literature indicates that with increasing sample size, PLS-SEM estimates improve with decreasing average error rates (Marcoulides \& Saunders, 2006). From the patient lists obtained from the targeted telemedicine centres, 500 residential addresses were randomly selected, consisting of proportionate samples from Dacope $(n=242)$, Devhata $(n=205)$ and Bera $(n=53)$ Upazila. Representation at the addresses was based on the mallintercept technique (Bush \& Hair Jr, 1985).

Patients' addresses and phone numbers were collected from rural telemedicine centres. They were contacted by phone and invited to participate in a one-hour survey at a telemedicine centre during office hours. Those unable to travel to the centres were asked to participate according to their convenience. Data were gathered through self-completion and interviewerfilled techniques to obtain high accuracy in the valid responses. Each interviewer administered five survey questionnaires per day. The study met the sampling target by obtaining 500 valid responses. All questionnaires were scrutinised for completeness. Eight samples were identified as incomplete and excluded; 492 samples were preserved for analysis. The survey's demographics are presented in Table 1. 


\begin{tabular}{llcc}
\hline \multicolumn{1}{c}{ Measure } & \multicolumn{1}{c}{ Items } & Frequency & Percentage (\%) \\
\hline Gender & Male & 206 & 41.9 \\
Age & Female & 286 & 58.1 \\
& 18 and $\leq 20$ & 64 & 13.0 \\
& $\geq 21$ and $\leq 30$ & 158 & 32.1 \\
& $\geq 31$ and $\leq 40$ & 106 & 21.5 \\
& $\geq 41$ and $\leq 50$ & 88 & 17.9 \\
Education & $>50$ & 76 & 15.4 \\
& Illiterate & 68 & 13.8 \\
& Primary & 104 & 21.0 \\
& Secondary & 178 & 36.2 \\
& Higher secondary & 64 & 13.0 \\
& Bachelor & 51 & 10.4 \\
& Masters and above & 27 & 5.5 \\
\hline
\end{tabular}

Table 1 - Demographic Characteristics of the Sample

\section{Data Analysis and Results}

PLS-SEM was employed to analyse the data set (Muthupoltotage \& Gardner, 2018) as it largely consists of latent constructs which cannot be measured directly requiring a set of indicators that serve as proxies (Hair Jr, Hult, Ringle, \& Sarstedt, 2017). A PLS-SEM path model incorporates two sets of linear equations - a measurement model specifying a construct and its corresponding indicators and a structural model specifying the relationship between exogenous and endogenous constructs (Henseler, Hubona, \& Ray, 2017). In PLS-SEM, indicators are also called items or manifest variables that are directly measured proxy variables containing raw data (Hair Jr et al., 2017). The structural model focuses on the research questions and hypothesis, addressing the two major questions about the inclusion and interrelationships of the constructs in the model (Henseler et al., 2017). Therefore, the PLSSEM technique is considered a more rigorous analysis for the proposed research model (Muthupoltotage \& Gardner, 2018).

\subsection{Measurement Model}

Table 2 illustrates the summary assessment of the 27 indicators associated with the eight assigned latent constructs (i.e., barriers to adoption [BA], lack of health staff motivation [LHSM], lack of ICT infrastructure [LICT], lack of organisational effectiveness [LOE], lack of quality of care [LQC], lack of resources [LR], lack of patient satisfaction [LSAT] and lack of trustworthiness [LT] of the reflective measurement model that tested internal consistency reliability, and convergent and discriminant validity. The relationships between the indicators and corresponding latent constructs were all significant $(p<.01)$. The standardised outer loadings of all indicators except one were higher than the threshold value (.70) (Roldán \& Sánchez-Franco, 2012), suggesting adequate, overall indicator reliability. Indicator BA1 (.698) was considered comparable to the threshold value. The average variance extracted (AVE) value of each construct exceeded the threshold value (>.5), thus indicating significant convergent validity (Hair Jr et al., 2017). These AVE values demonstrate that each construct explains the variance of over half of their corresponding indicators, confirming acceptable convergent validity (Roldán \& Sánchez-Franco, 2012). Both Cronbach's alpha and composite reliability exceeded their threshold values (>.70), confirming statistical significance of the model and demonstrating strong evidence of internal consistency reliability (Hair Jr et al., 2017). 


\begin{tabular}{|c|c|c|c|c|c|c|c|}
\hline Latent Constructs & Indicators & $\begin{array}{l}\text { Standardised } \\
\text { Loading }\end{array}$ & AVE & $\mathrm{CR}$ & $\begin{array}{c}\text { Cronbach's } \\
\text { Alpha }\end{array}$ & $R^{2}$ & $\begin{array}{l}\text { Adjusted } \\
\qquad R^{2}\end{array}$ \\
\hline \multirow[t]{4}{*}{ Barriers to adoption } & BA1 & .698 & .556 & .834 & .737 & .625 & .622 \\
\hline & BA2 & .747 & & & & & \\
\hline & BA3 & .773 & & & & & \\
\hline & BA4 & .763 & & & & & \\
\hline \multirow{2}{*}{$\begin{array}{l}\text { Lack of health staff } \\
\text { motivation }\end{array}$} & LHSM1 & .905 & .786 & .880 & .730 & & \\
\hline & LHSM4 & .868 & & & & & \\
\hline \multirow[t]{4}{*}{ Lack of ICT Infrastructure } & LICT1 & .840 & .693 & .900 & .852 & .668 & .668 \\
\hline & LICT2 & .839 & & & & & \\
\hline & LICT3 & .853 & & & & & \\
\hline & LICT4 & .797 & & & & & \\
\hline \multirow[t]{5}{*}{$\begin{array}{l}\text { Lack of organisational } \\
\text { effectiveness }\end{array}$} & LOE1 & .851 & .706 & .923 & .895 & .730 & .730 \\
\hline & LOE2 & .864 & & & & & \\
\hline & LOE3 & .852 & & & & & \\
\hline & LOE4 & .839 & & & & & \\
\hline & LOE5 & .793 & & & & & \\
\hline \multirow[t]{2}{*}{ Lack of quality of care } & LQC2 & .913 & .837 & .912 & .806 & .538 & .537 \\
\hline & LQC4 & .917 & & & & & \\
\hline \multirow[t]{4}{*}{ Lack of resources } & LR1 & .812 & .684 & .897 & .846 & & \\
\hline & LR2 & .827 & & & & & \\
\hline & LR3 & .819 & & & & & \\
\hline & LR4 & .850 & & & & & \\
\hline \multirow[t]{2}{*}{ Lack of patient satisfaction } & LSAT1 & .919 & .826 & .905 & .790 & .493 & .491 \\
\hline & LSAT2 & .898 & & & & & \\
\hline \multirow[t]{4}{*}{ Lack of trustworthiness } & LT2 & .803 & .669 & .890 & .836 & .432 & .430 \\
\hline & LT3 & .826 & & & & & \\
\hline & LT4 & .838 & & & & & \\
\hline & LT6 & .803 & & & & & \\
\hline
\end{tabular}

Table 2 - Convergent Validity and Reliability Statistics of the Sample

The square root of each construct's AVE was higher than the correlation with other constructs except for LICT, confirming the construct's acceptable discriminant validity (see Table 3) (Sarstedt, Wilczynski, \& Melewar, 2013). To verify the discriminant validity of LICT, the crossloadings index was investigated and found to be higher than the cross-loading values of all other constructs, supporting acceptable discriminant validity (Hair Jr et al., 2017). The literature suggests that this test is highly recommended to ensure no indicators are incorrectly assigned to a construct (Henseler et al., 2017).

\begin{tabular}{lllllllll}
\hline & BA & LHSM & LICT & LOE & LQC & LR & LSAT & LT \\
\hline BA & .746 & & & & & & & \\
LHSM & .549 & .887 & & & & & & \\
LICT & .489 & .251 & .832 & & & & & \\
LOE & .497 & .197 & .855 & .840 & & & & \\
LQC & .504 & .727 & .280 & .245 & .915 & & & \\
LR & .436 & .230 & .818 & .770 & .242 & .827 & & \\
LSAT & .693 & .656 & .279 & .251 & .648 & .232 & .909 & \\
LT & .539 & .297 & .582 & .631 & .292 & .551 & .337 & .818 \\
\hline
\end{tabular}

Note. The square root of AVE in bold.

Table 3 - Discriminant Validity Coefficients 


\subsection{Structural Model}

The structural model was developed to describe the relationships among the latent constructs and examine their significance (Roldán \& Sánchez-Franco, 2012). A bootstrapping technique using 5000 iterations was used to test the statistical significance of the relationships between endogenous and exogenous latent constructs in the structural path models (Hair Jr et al., 2017). The structural model and hypothesised relationships between the endogenous and exogenous constructs were tested using a standardised path coefficient $(\beta)$ and $t$-statistics (see Tables 2 and 4 ) at $p<.01$, which conservative researchers have used in their research (Hair Jr et al., 2017). The threshold critical $t$-values ( $\alpha$; two-tailed test) at a significance level of $\alpha=.05, \alpha=.01$ and $\alpha=.10$ were 1.96, 2.57 and 1.65, respectively (Hair Jr et al., 2017).

The structural model revealed that all 12 hypotheses were supported by the relationships at the $p<.01$ significance level (see Figure 2). The results (see Tables 2 and 4 ) authenticate that the four proposed latent constructs had significant effects on barriers to telemedicine adoption. The findings show that the relationships between LOE and BA $(\beta=.228, t=4.587, p<.01)$, LHSM and BA $(\beta=.126, t=2.992, p<.01)$, LSAT and BA $(\beta=.488, t=10.061, p<.01)$ and LT and BA $(\beta=.193$, $t=3.536, p<.01$ ) were statistically significant, confirming support for H1, H8, H10 and H12 (see Table 4 ). An $R^{2} \approx .622$ indicates that about $62 \%$ of the variance (i.e., BA) in the model was jointly explained by LOE, LHSM, LSAT and LT. The results were close to a substantial $R^{2}$ value (i.e., $67 \%$ ) (Henseler, Ringle, \& Sinkovics, 2009), suggesting high predictive capability of the model. Further, the literature indicates that $R^{2}$ demonstrates each construct's significance and its associative contribution to the overall $R^{2}$ (Wilson, 2010). Thus, the findings conclude that LOE, LHSM, LSAT and LT are four significant barriers impeding the adoption of current telemedicine projects in rural public hospital settings.

\begin{tabular}{llccccc}
\hline & Hypothesis & Path coefficient $(\boldsymbol{\beta})$ & SE & $\boldsymbol{t}$ & $\boldsymbol{p}$ & Decision \\
\hline H1 & LOE $\rightarrow$ BA & $.228^{* * *}$ & .050 & 4.587 & .000 & Supported \\
H2 & LOE $\rightarrow$ LT & $.583^{* * *}$ & .046 & 12.698 & .000 & Supported \\
H3 & LICT $\rightarrow$ LOE & $.855^{* * *}$ & .020 & 42.560 & .000 & Supported \\
H4 & LICT $\rightarrow$ LQC & $.104^{* * *}$ & .038 & 2.712 & .007 & Supported \\
H5 & LR $\rightarrow$ LICT & $.818^{* * *}$ & .023 & 35.733 & .000 & Supported \\
H6 & LHSM $\rightarrow$ LQC & $.701^{* * *}$ & .032 & 21.756 & .000 & Supported \\
H7 & LHSM $\rightarrow$ LSAT & $.392^{* * *}$ & .058 & 6.806 & .000 & Supported \\
H8 & LHSM $\rightarrow$ BA & $.126^{* * *}$ & .042 & 2.992 & .003 & Supported \\
H9 & LQC $\rightarrow$ LSAT & $.363^{* * *}$ & .060 & 6.068 & .000 & Supported \\
H10 & LSAT $\rightarrow$ BA & $.488^{* * *}$ & .048 & 10.061 & .000 & Supported \\
H11 & LSAT $\rightarrow$ LT & $.190^{* * *}$ & .035 & 5.373 & .000 & Supported \\
H12 & LT $\rightarrow$ BA & $.193^{* * *}$ & .055 & 3.536 & .000 & Supported \\
\hline
\end{tabular}

Note. ${ }^{*} p<.10 ;{ }^{* *} p<.05 ;{ }^{* * *} p<.01$ (two-tailed) confidence intervals for significance testing.

Table 4 - Structural Estimation of t-values and p-values for the Structural Model 


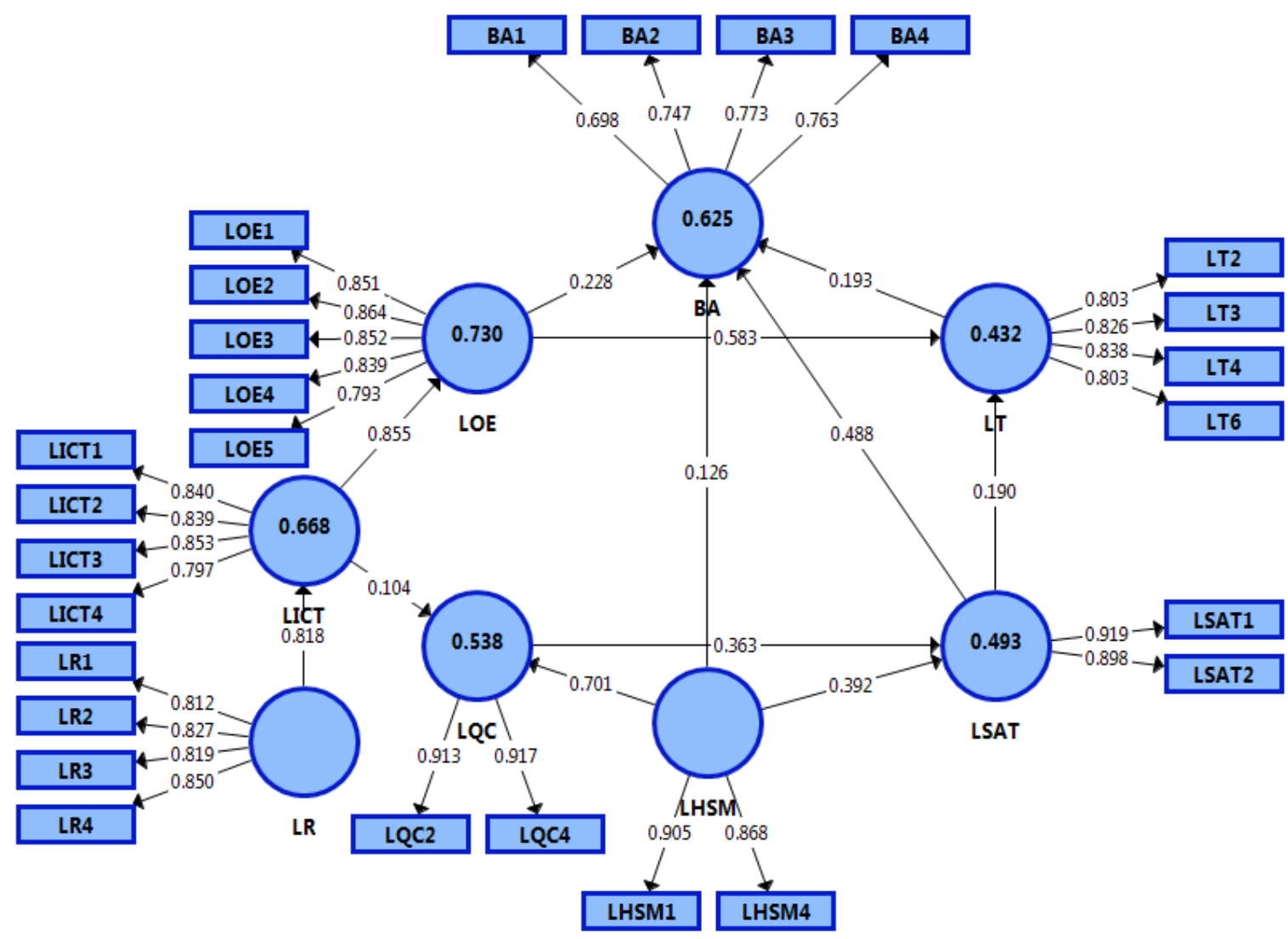

Figure 2. Final PLS-SEM structural model for telemedicine adoption barriers.

The structural model further revealed that eight other hypotheses were supported at the $p<$ .01 significance level (see Figure 2). The relationships between LOE and LT ( $\beta=.583, t=12.698$, $p<.01)$, LICT and LOE $(\beta=.855, t=42.560, p<.01)$, LICT and LQC $(\beta=.104, t=2.712, p<.01)$, LR and LICT $(\beta=.818, t=35.733, p<.01)$, LHSM and LQC $(\beta=.701, I=21.756, p<.01)$, LHSM and LSAT $(\beta=.392, t=6.806, p<.01)$, LQC and LSAT $(\beta=.363, t=6.068, p<.01)$, and LSAT and LT $(\beta=.190, t=5.373, p<.01)$ were statistically significant, confirming support for $\mathrm{H} 2, \mathrm{H} 3, \mathrm{H} 4$, H5, H6, H7, H9 and H11 (see Table 4). However, some of these constructs were not significantly related to the barriers to telemedicine adoption. Our findings revealed that these constructs have no direct effect on BA, but strongly affect their endogenous latent constructs. Consistent with these findings, we can conclude that these constructs have a substantial indirect impact on the adoption of telemedicine projects in rural public hospital settings in Bangladesh. Further, $R^{2}$ was significant for each these constructs and their contribution to the structural model's overall $R^{2}$ (see Table 4) (Wilson, 2010). These constructs may need further research into the significance of their contributions to barriers to telemedicine adoption.

\section{Discussion}

\subsection{Summary of Findings}

These findings are based on the opinions of patients who experienced telemedicine services. The survey excluded non-users because patients in Bangladesh cannot access telemedicine services without physician referral. Four substantial barriers offer considerable resistance to telemedicine adoption. Discussion of these findings will elucidate on the concerns of how these barriers contribute to broader adoption complexities requiring appropriately guided 
action to make telemedicine sustainable. It is anticipated that identifying influential barriers to telemedicine adoption will provide insight for promoting efficiency in telemedicine clinical practices and advancing its sustainability in Bangladesh's healthcare industry. Organisational barriers, health staff motivation, patient satisfaction and trustworthiness appeared to have a predominant adverse effect inhibiting telemedicine's successful integration into Bangladesh's clinical practices.

\subsection{Organisational Barriers}

Lack of organisational effectiveness is a significant telemedicine adoption barrier, indicating that current telemedicine projects fail to meet their organisational goals regarding effectivity measures. Effective tele-monitoring systems have been shown to reduce hospitalisations and mortality risk among patients with chronic heart failure (Kim, Gellis, Bradway, \& Kenaley, 2018). Many e-Health project plans fail due to inadequate organisational policy integration into practice (Gagnon et al., 2009). Similar research (K. Cresswell \& Sheikh, 2013) revealed that organisational efficiency is a major barrier to telemedicine adoption which needs to be quantified. Evans (2015) suggested that successful telemedicine adoption relies on the organisational restructuring of internal processes, and the integration of new patient care policies and procedures which allow health seekers and health providers onto a telemedicine health care platform. The results authenticate that health organisations, strategic planning, infrastructural design, clear operational guidelines, and active management support have received insufficient attention in current telemedicine projects. Therefore, implementation of these practices along with sufficient human resources could foster telemedicine effectiveness in rural public hospital settings.

\subsection{Health Staff Motivation Barriers}

The second barrier is a lack of staff motivation, which the results demonstrate had a significant effect on telemedicine adoption barriers in rural public hospital settings. Health staff motivation is vital to organisational effectiveness because they are the frontline user group of telemedicine service processes (Ajami \& Bagheri-Tadi, 2013). Health staff performance determines how well an organisation functions (Jayasuriya et al., 2014). The findings imply that present telemedicine projects do not adequately motivate health staff to enable an effective working environment, facilitate financial and professional benefits or allocate adequate resources for achieving patient health expectations. Observations suggested that in an Upazila rural hospital, physicians experienced heavy workloads and telemedicine patients were often an additional burden, causing professional frustration.

Physicians are reluctant to serve in rural hospitals due to limited support, insufficient resources, uncomfortable conditions and isolation from professional colleagues (Henderson \& Tulloch, 2008). Observations indicated that physicians in rural hospitals focused on general patients rather than telemedicine, resulting in increased wait times for telemedicine patients. Present telemedicine projects do not dedicate physicians to telemedicine centres, and some telemedicine patients are serviced by ICT support engineers who directly consult with specialised physicians. Current projects have not focused on this issue in telemedicine practices. Therefore, well-trained physicians should be dedicated to rural telemedicine centres and responsible for supervising telemedicine patients.

The results show that a lack of health staff motivation had substantial effects on lack of quality of care and patient satisfaction. This suggests that health workers' motivation is an influential 
determinant to enhance telemedicine service quality, contributing towards high patient satisfaction. Poor service quality is of critical concern in developing countries and partly contributes to low healthcare staff motivation (Chandler et al., 2009). Financial incentives and personal and professional benefits can stimulate health staff motivation to perform their assigned tasks, resulting in higher service quality and patient satisfaction (Lohmann et al., 2018). The findings suggest that the total service duration of telemedicine physicians in rural centres should be considered for those entitled to specialist medical degrees. Similarly, telemedicine support engineers should be recognised to motivate them as enablers of organisational success (Franco et al., 2002), but observations suggested they were frustrated due to low remuneration and were seeking opportunities with other providers. A primary concern in developing countries is financial accessibility, namely the government's inability to provide sufficient funds to the public health system, low remuneration of health staff and lack of medical supplies (Peters et al., 2008). To overcome this barrier, employer performance-based financial benefits are needed to convince health staff of the value of telemedicine services (E. Miller, 2010).

\subsection{Patient Satisfaction Barriers}

Lack of patient satisfaction is the third barrier. This significant finding indicates that current telemedicine projects fail to sufficiently satisfy their patients, suggesting that patients who perceive a lack of accessibility and poor service quality are more likely to be dissatisfied with telemedicine. Patient satisfaction is a significant health outcome indicator (Greenslade \& Jimmieson, 2011) and critical to organisational performance in hospital settings (Koné Péfoyo \& Wodchis, 2013). A satisfied patient will likely return to the services and share their positive experiences (Hill \& Doddato, 2002). A recent study (Williams et al., 2018) found that postoperative telemedicine patients have a satisfaction rate as high as $111 \%$ and prefer telemedicine follow-up.

Observations indicated that current telemedicine practices are non-committal in terms of systems accessibility. Official opening hours are limited, contributing to patient dissatisfaction for those unable to access services after travelling long distances and paying additional travelling costs. The literature indicates that personnel, physical space and internet access are additional barriers in rural hospital settings (Garrett et al., 2006). Interestingly, to bolster patient satisfaction, current telemedicine does not offer an emergency telemedicine service facility, a specialised diagnosis facility in a rural centre or assurance of prescribed medicine availability in a local pharmacy. Patients should have continual access to a telemedicine clinical team, promoting their health and wellbeing (Freed et al., 2018). A study identified a positive relationship between service quality and patient satisfaction in healthcare interventions (Lee \& Yom, 2007), suggesting that satisfaction is critical in healthcare quality assessment and organisational loyalty, reflecting the core issues affecting the longevity of current healthcare industries (Elbeck, 1987). These findings are informative and relate to patient concerns regarding telemedicine accessibility and service quality.

\subsection{Patient Trustworthiness Barriers}

The fourth significant barrier is a lack of trustworthiness, which the findings suggest had a significant effect on telemedicine adoption. Trustworthiness in telemedicine can be established by fulfilling four essential beliefs: ability, benevolence, integrity and predictability (Akter et al., 2011; Mayer \& Davis, 1999). The results indicate that current telemedicine projects fail to achieve these beliefs, indicating that patients do not sufficiently trust current service 
standards. ICT-based healthcare services are often insufficiently funded, operate in a resourcepoor environment and, when accessible, are often dysfunctional or unresponsive (Akter et al., 2011). These factors contribute to low trustworthiness of the health system (Akter et al., 2011).

Observations suggested that existing telemedicine health facilities were inadequate regarding resource and performance measures. Space, physical resources and medical and operational ICT support were insufficiently allocated to telemedicine services. Three to four patients were consistently present in the consultation room. From a sociocultural perspective, many patients are uncomfortable disclosing disease-related issues in front of other patients and so their disease-related privacy and confidentiality is unprotected. Further, current telemedicine centres have not yet established convenient service hours, timely and easy referral systems, prompt responsiveness to patient needs or better patient supervision concerning patient care and supportiveness. Since telemedicine entails the electronic transmission and storage of patient health-related data (Chang, 2015), it is essential for health providers to keep secure data privacy and confidentiality.

\subsection{Other Barriers}

The results show that a lack of ICT support, resources and quality of care indirectly affect adoption barriers through a lack of organisational effectiveness, health staff motivation, patient satisfaction and trustworthiness. Lack of ICT infrastructure, allocation of resources and quality of care have no direct effect on telemedicine adoption barriers but strongly affect endogenous latent constructs. Insufficient power supply and internet facilities, bandwidth expenses and telemedicine equipment might be primary challenges to telemedicine implementation in Bangladesh (Hasan, 2012). These are important factors in telemedicine implementation (Lewis et al., 2012). Equipment costs and maintenance, poor technical expertise and a lack of coordination, staffing and technical infrastructure are reported telemedicine adoption barriers (Larsen, Hudnall Stamm, Davis, \& Magaletta, 2004). Researchers worldwide could test these factors and compare their findings to further understand telemedicine adoption barriers in rural settings. Therefore, strong ICT infrastructure, adequate financial and human resources, uninterrupted power supply and high internet speed and connectivity are required to expedite telemedicine adoption for the medically underprivileged rural community.

\subsection{Implications}

This unique study develops an original framework for a conceptual model that brings to light the relationships between telemedicine and its subsequent adoption barriers within the context of rural public hospital settings in Bangladesh. This study has made several contributions to the literature. First, it has provided significant practical implications that can be applied to the health-related literature. Second, this study investigated potential barriers impeding the adoption of telemedicine healthcare services in a developing country like Bangladesh. Third, it has identified four exemplary barriers to telemedicine adoption-lack of organisational effectiveness, health staff motivation, patient satisfaction and trustworthiness - that offer considerable resistance to the adoption of current telemedicine projects in rural Bangladesh's public hospitals settings.

To the authors' knowledge, no studies were available to guide research into factors causing the low rate of telemedicine adoption in Bangladesh's rural public hospitals. Little research has investigated these barriers from a patient perspective, representing a considerable 
knowledge gap in the literature. The authors believe that the proposed model contributes significantly to the literature, particularly in the context of developing nations and provides practical guidelines for expediting telemedicine adoption in rural settings in emerging countries. The empirical findings may clarify the causative factors of existing telemedicine project adoption. The findings may also institutionalise favourable policy guidelines for successful telemedicine service adoption in rural settings, including the improvement of healthcare industries in both Bangladesh and similar emerging economies in a global context.

\subsection{Conclusions}

This study explored a range of barriers to telemedicine adoption in Bangladesh's current public projects that have not been addressed in the literature. Lack of organisational effectiveness, quality of care, trustworthiness and health staff motivation were identified as dominant barriers. This research is significant and hopes to build telemedicine into an institutionalised health infrastructure for providing better quality care with greater flexibility through modernised, specialised healthcare support for medically underprivileged rural communities in Bangladesh. Rural and remote populations still have inadequate access to dedicated public medical facilities and private after-hours medical practitioners.

All barriers identified in this research are considerable threats to sustaining telemedicine projects but are believed to be manageable by Bangladesh's policymakers, stakeholders and implementers. An active telemedicine action plan and regulations are suggested to break down the adoption barriers and achieve organisational goals. Although successful telemedicine adoption is considered a formidable task, especially in such a resource-poor country as Bangladesh, the findings provide to the government, policymakers, implementers and stakeholders a clear vision regarding the causative adoption factors emerging from current telemedicine projects. The findings will also be useful in developing appropriate policy guidelines for the betterment of healthcare industries in Bangladesh and similar emerging economies.

\subsection{Limitations and Future Research}

Some limitations exist in this research. First, a small proportion of telemedicine centres were surveyed. Future studies can include additional telemedicine centres to test findings' generalisability. Second, this study reflected only the views of health seekers. Future research should consist of health providers' views to understand more clearly telemedicine adoption barriers. Third, only rural public health providers were included in this study. Private telemedicine providers can be included in future research to understand their differences in service interests and telemedicine adoption barriers. Finally, this study was limited to Bangladesh. Combining this study with cross-sectional data from similar developing countries can provide a broader view of telemedicine adoption barriers in a global context.

\subsection{Research Highlights}

- The unprecedented data collection exercise involving months of field work in the most remote areas of Bangladesh provides unique and valuable insights into remote people's views regarding telemedicine services.

- Four significant barriers to telemedicine adoption were identified and confirmed namely, lack of organisational effectiveness, health staff motivation, patient satisfaction, and trustworthiness. A paucity of theses leads to significant resistance to the adoption of telemedicine projects in rural Bangladesh's public hospital's settings. 
- The structural equation modeling method used to validate a structural model showing interactions and persistence of interaction of telemedicine adoption barriers.

- A validated, robust functional model that can be used to investigate telemedicine adoption barriers in emerging economies was confirmed.

\section{Acknowledgements}

The authors gratefully acknowledge the participants in the study and the health bodies of Directorate General of Health Services, MOHFW of Bangladesh, who helped in carrying out this research.

\section{References}

Ahmed, T., Bloom, G., Iqbal, M., Lucas, H., Rasheed, S., Waldman, L., Bhuiya, A. (2014). Ehealth and M-Health in Bangladesh: Opportunities and Challenges. (No. IDS Evidence Report; 60). IDS.

Ajami, S., \& Bagheri-Tadi, T. (2013). Barriers for adopting electronic health records (EHRs) by physicians. Acta Informatica Medica, 21(2), 129.

Akter, M. S., Upal, M., \& Hani, U. (2008). Service quality perception and satisfaction: a study over sub-urban public hospitals in Bangladesh. Journal of Services Research, 125.

Akter, S., D'Ambra, J., \& Ray, P. (2011). Trustworthiness in mHealth information services: an assessment of a hierarchical model with mediating and moderating effects using partial least squares (PLS). Journal of the Association for Information Science and Technology, 62(1), 100-116.

Akter, S., Upal, M., \& Hani, U. (2008). Service quality perception and satisfaction: a study over sub-urban public hospitals in Bangladesh. Journal of Services Research, 8(S1), S125.

Alaboudi, A., Atkins, A., Sharp, B., Balkhair, A., Alzahrani, M., \& Sunbul, T. (2016). Barriers and challenges in adopting Saudi telemedicine network: The perceptions of decision makers of healthcare facilities in Saudi Arabia. Journal of infection and public health, 9(6), 725-733.

Anderson, J. G. (2007). Social, ethical and legal barriers to e-health. International journal of medical informatics, 76(5), 480-483.

Bigna, J. J. R., Noubiap, J. J. N., Plottel, C. S., Kouanfack, C., \& Koulla-Shiro, S. (2014). Barriers to the implementation of mobile phone reminders in pediatric HIV care: a pre-trial analysis of the Cameroonian MORE CARE study. BMC health services research, 14(1), 523.

Boonstra, A., \& Broekhuis, M. (2010). Barriers to the acceptance of electronic medical records by physicians from systematic review to taxonomy and interventions. BMC health services research, 10(1), 231.

Bullock, D. R., Vehe, R. K., Zhang, L., \& Correll, C. K. (2017). Telemedicine and other care models in pediatric rheumatology: an exploratory study of parents' perceptions of barriers to care and care preferences. Pediatric Rheumatology, 15(1), 55.

Burt, C. W., \& Sisk, J. E. (2005). Which physicians and practices are using electronic medical records? Health affairs, 24(5), 1334-1343. 
Bush, A. J., \& Hair Jr, J. F. (1985). An assessment of the mall intercept as a data collection method. Journal of Marketing research, 158-167.

Cajita, M. I., Hodgson, N. A., Lam, K. W., Yoo, S., \& Han, H.-R. (2018). Facilitators of and Barriers to mHealth Adoption in Older Adults With Heart Failure. CIN: Computers, Informatics, Nursing, 36(8), 376-382.

Call, V. R., Erickson, L. D., Dailey, N. K., Hicken, B. L., Rupper, R., Yorgason, J. B., \& Bair, B. (2015). Attitudes toward telemedicine in urban, rural, and highly rural communities. Telemedicine and e-Health, 21(8), 644-651.

Chandler, C. I. R., Chonya, S., Mtei, F., Reyburn, H., \& Whitty, C. J. M. (2009). Motivation, money and respect: A mixed-method study of Tanzanian non-physician clinicians. Social science $\mathcal{E}$ medicine, 68(11), 2078-2088. doi:10.1016/j.socscimed.2009.03.007

Chang, H. (2015). Evaluation framework for telemedicine using the logical framework approach and a fishbone diagram. Healthcare informatics research, 21(4), 230-238.

Cresswell, J. W., \& Clark, V. L. P. (2011). Designing and conducting mixed methods resaerch. (2nd edition).

Cresswell, K., \& Sheikh, A. (2013). Organizational issues in the implementation and adoption of health information technology innovations: an interpretative review. International journal of medical informatics, 82(5), e73-e86.

De Bustos, E. M., Moulin, T., \& Audebert, H. J. (2009). Barriers, legal issues, limitations and ongoing questions in telemedicine applied to stroke. Cerebrovascular Diseases, 27(Suppl. 4), 36-39.

de la Torre Díez, I., Alonso, S. G., Hamrioui, S., López-Coronado, M., \& Cruz, E. M. (2018). Systematic Review about QoS and QoE in Telemedicine and eHealth Services and Applications. Journal of medical systems, 42(10), 182.

Elbeck, M. (1987). An approach to client satisfaction measurement as an attribute of health service quality. Health Care Management Review, 12(3), 47-52.

Evans, P. R. (2015). An exploration of the perceptions of a US Midwest acute care hospital organization regarding the adoption and acceptance of telemedicine. Capella University,

Faber, S., van Geenhuizen, M., \& de Reuver, M. (2017). eHealth adoption factors in medical hospitals: A focus on the Netherlands. International journal of medical informatics, 100, $77-$ 89.

Fanta, G. B., Pretorius, L., \& Erasmus, L. (2015). An evaluation of eHealth systems implementation frameworks for sustainability in resource constrained environments: a literature review. Paper presented at the IAMOT 2015 Conference Proceedings, Cape Town.

Franco, L. M., Bennett, S., \& Kanfer, R. (2002). Health sector reform and public sector health worker motivation: a conceptual framework. Social science $\mathcal{E}$ medicine, 54(8), 1255-1266.

Freed, J., Lowe, C., Flodgren, G., Binks, R., Doughty, K., \& Kolsi, J. (2018). Telemedicine: Is it really worth it? A perspective from evidence and experience. Journal of innovation in health informatics, 25(1), 14-18. doi:10.14236/jhi.v25i1.957 
Gagnon, M.-P., Shaw, N., Sicotte, C., Mathieu, L., Leduc, Y., Duplantie, J., . . Légaré, F. (2009). Users' perspectives of barriers and facilitators to implementing EHR in Canada: A study protocol. Implementation Science, 4(1), 20.

Garrett, P., Brown, C. A., Hart-Hester, S., Hamadain, E., Dixon, C., Pierce, W., \& Rudman, W. J. (2006). Identifying barriers to the adoption of new technology in rural hospitals: a case report. Perspectives in health information management/AHIMA, American Health Information Management Association, 3.

Gibson, K. L., Coulson, H., Miles, R., Kakekakekung, C., Daniels, E., \& O'donnell, S. (2011). Conversations on telemental health: listening to remote and rural First Nations communities. Rural and Remote Health, 11(2), 1656-1674.

Gravel, K., Légaré, F., \& Graham, I. D. (2006). Barriers and facilitators to implementing shared decision-making in clinical practice: a systematic review of health professionals' perceptions. Implementation Science, 1(1), 16.

Greenslade, J. H., \& Jimmieson, N. L. (2011). Organizational factors impacting on patient satisfaction: A cross sectional examination of service climate and linkages to nurses' effort and performance. International Journal of Nursing Studies, 48(10), 1188-1198. doi:10.1016/j.ijnurstu.2011.04.004

Hage, E., Roo, J. P., van Offenbeek, M. A., \& Boonstra, A. (2013). Implementation factors and their effect on e-Health service adoption in rural communities: a systematic literature review. BMC health services research, 13(1), 19.

Hair Jr, J. F., Hult, G. T. M., Ringle, C., \& Sarstedt, M. (2017). A primer on partial least squares structural equation modeling (PLS-SEM): Sage Publications.

Hamid, S. A., Ahsan, S. M., Begum, A., \& Asif, C. A. A. (2015). Inequity in formal health care use: Evidence from rural Bangladesh. Journal of International Development, 27(1), 36-54.

Hasan, J. (2012). Effective telemedicine project in Bangladesh: Special focus on diabetes health care delivery in a tertiary care in Bangladesh. Telematics and Informatics, 29(2), 211-218.

Henderson, L. N., \& Tulloch, J. (2008). Incentives for retaining and motivating health workers in Pacific and Asian countries. Human resources for health, 6(1), 18-18. doi:10.1186/14784491-6-18

Henseler, J., Hubona, G., \& Ray, P. A. (2017). Partial least squares path modeling: Updated guidelines. In Partial Least Squares Path Modeling (pp. 19-39): Springer.

Henseler, J., Ringle, C. M., \& Sinkovics, R. R. (2009). The use of partial least squares path modeling in international marketing. In New challenges to international marketing (pp. 277319): Emerald Group Publishing Limited.

Hill, M. H., \& Doddato, T. (2002). Relationships among patient satisfaction, intent to return, and intent to recommend services provided by an academic nursing center. Journal of cultural diversity, 9(4), 108-112.

Hoque, M. R. (2016). An empirical study of mHealth adoption in a developing country: the moderating effect of gender concern. BMC medical informatics and decision making, 16(1), 51. 
Hoque, M. R., \& Bao, Y. (2015). Cultural Influence on Adoption and Use of e-Health: Evidence in Bangladesh. Telemedicine and e-Health, 21(10), 845-851. doi:10.1089/tmj.2014.0128

Hoque, M. R., Karim, M. R., \& Amin, M. B. (2015). Factors Affecting the Adoption of mHealth Services among Young Citizen: A Structural Equation Modeling (SEM) Approach. Asian Business Review, 5(2), 60-65.

Hoque, M. R., Mazmum, M., \& Bao, Y. (2014). e-Health in Bangladesh: current status, challenges, and future direction. Int Tech Manag Rev, 4(2), 87-96.

Hoque, R., \& Sorwar, G. (2017). Understanding factors influencing the adoption of mHealth by the elderly: An extension of the UTAUT model. International journal of medical informatics, 101, 75-84. doi:10.1016/j.ijmedinf.2017.02.002

Hossain, N., Yokota, F., Sultana, N., \& Ahmed, A. (2018). Factors Influencing Rural End-Users' Acceptance of e-Health in Developing Countries: A study on Portable Health Clinic in Bangladesh. Telemedicine journal and e-health : the official journal of the American Telemedicine Association. doi:10.1089/tmj.2018.0039

Islam, M. M., Touray, M., Yang, H. C., Poly, T. N., Nguyen, P. A., Li, Y. C., \& Syed, A. S. (2017). E-Health Literacy and Health Information Seeking Behavior Among University Students in Bangladesh. Paper presented at the 16th World Congress of Medical and Health Informatics: Precision Healthcare through Informatics, MedInfo 2017.

Jang-Jaccard, J., Nepal, S., Alem, L., \& Li, J. (2014). Barriers for delivering telehealth in rural Australia: a review based on Australian trials and studies. Telemedicine and e-Health, 20(5), 496-504.

Jayasuriya, R., Jayasinghe, U. W., \& Wang, Q. (2014). Health worker performance in rural health organizations in low- and middle-income countries: Do organizational factors predict non-task performance? Social science $\mathcal{E}$ medicine, 113, 1-4. doi:10.1016/j.socscimed.2014.04.042

Johnson, K. B. (2001). Barriers that impede the adoption of pediatric information technology. Archives of pediatrics $\mathcal{E}$ adolescent medicine, 155(12), 1374-1379.

Khan, M., Hossain, S., Hasan, M., \& Clement, C. K. (2012). Barriers to the introduction of ICT into education in developing countries: The example of Bangladesh. Online Submission, $5(2), 61-80$.

Kiberu, V. M., Mars, M., \& Scott, R. E. (2017). Barriers and opportunities to implementation of sustainable e-Health programmes in Uganda: A literature review. African journal of primary health care $\mathcal{E}$ family medicine, $9(1)$.

Kifle, M., Mbarika, V. W., Tsuma, C., Wilkerson, D., \& Tan, J. (2008). A telemedicine transfer model for Sub-Saharan Africa. Proceedings of the 41st Annual Hawaii International Conference on System Sciences,

Kim, E., Gellis, Z. D., Bradway, C., \& Kenaley, B. (2018). Key determinants to using telehealth technology to serve medically ill and depressed homebound older adults. Journal of gerontological social work, 1-24. doi:10.1080/01634372.2018.1499575 
Koivunen, M., \& Saranto, K. (2018). Nursing professionals' experiences of the facilitators and barriers to the use of telehealth applications: a systematic review of qualitative studies. Scandinavian journal of caring sciences, 32(1), 24-44.

Koné Péfoyo, A. J., \& Wodchis, W. P. (2013). Organizational performance impacting patient satisfaction in Ontario hospitals: a multilevel analysis. BMC research notes, 6(1), 509-509. doi:10.1186/1756-0500-6-509

Kruse, C. S., Atkins, J. M., Baker, T. D., Gonzales, E. N., Paul, J. L., \& Brooks, M. (2018). Factors influencing the adoption of telemedicine for treatment of military veterans with posttraumatic stress disorder. Journal of Rehabilitation Medicine, 50(5), 385-392.

Lankton, N. K., \& Wilson, E. V. (2007). Factors influencing expectations of e-health services within a direct-effects model of user satisfaction. E-Service Journal, 5(2), 85-112.

Larsen, D., Hudnall Stamm, B., Davis, K., \& Magaletta, P. R. (2004). Prison telemedicine and telehealth utilization in the United States: state and federal perceptions of benefits and barriers. Telemedicine Journal \& e-Health, 10(Supplement 2), S-81-S-90.

Leaming, L. E. (2007). Barriers to physician adoption of telemedicine and best practices for overcoming these barriers. (Doctoral dissertation, Medical University of South Carolina).

Lee, M. A., \& Yom, Y.-H. (2007). A comparative study of patients' and nurses' perceptions of the quality of nursing services, satisfaction and intent to revisit the hospital: A questionnaire survey. International Journal of Nursing Studies, 44(4), 545-555. doi:10.1016/j.ijnurstu.2006.03.006

LeRouge, C., \& Garfield, M. J. (2013). Crossing the telemedicine chasm: have the US barriers to widespread adoption of telemedicine been significantly reduced? International journal of environmental research and public health, 10(12), 6472-6484.

Lewis, T., Synowiec, C., Lagomarsino, G., \& Schweitzer, J. (2012). E-health in low-and middleincome countries: findings from the Center for Health Market Innovations. Bulletin of the World Health Organization, 90(5), 332-340.

Lin, C., Lin, I.-C., \& Roan, J. (2012). Barriers to physicians' adoption of healthcare information technology: an empirical study on multiple hospitals. Journal of medical systems, 36(3), 1965-1977.

Lluch, M. (2011). Healthcare professionals' organisational barriers to health information technologies-A literature review. International journal of medical informatics, 80(12), 849862.

Lohmann, J., Muula, A. S., Houlfort, N., \& De Allegri, M. (2018). How does performance-based financing affect health workers' intrinsic motivation? A self-determination theory-based mixed-methods study in Malawi. Social science $\mathcal{E}$ medicine, 208, 1-8.

Marcoulides, G. A., \& Saunders, C. (2006). Editor's comments: PLS: a silver bullet? MIS quarterly, iii-ix.

Mars, M. (2013). Telemedicine and advances in urban and rural healthcare delivery in Africa. Progress in cardiovascular diseases, 56(3), 326-335.

Martin, A. B., Probst, J. C., Shah, K., Chen, Z., \& Garr, D. (2012). Differences in readiness between rural hospitals and primary care providers for telemedicine adoption and 
implementation: findings from a statewide telemedicine survey. The Journal of Rural Health, 28(1), 8-15.

Marzagão, D. S. L., \& Carvalho, M. M. (2016). Critical success factors for Six Sigma projects. International Journal of Project Management, 34(8), 1505-1518.

Mathieson, K., Leafman, J. S., \& Horton, M. B. (2017). Access to Digital Communication Technology and Perceptions of Telemedicine for Patient Education among American Indian Patients with Diabetes. Journal of Health Care for the Poor and Underserved, 28(4), 1522-1536. doi:10.1353/hpu.2017.0131

Mayer, R. C., \& Davis, J. H. (1999). The effect of the performance appraisal system on trust for management: A field quasi-experiment. Journal of applied psychology, 84(1), 123.

Menachemi, N., Burke, D. E., \& Ayers, D. J. (2004). Factors affecting the adoption of telemedicine-a multiple adopter perspective. Journal of medical systems, 28(6), 617-632.

Miller, E. (2010). Telemedicine and the provider-patient relationship: What we know so far. Report prepared for the Nuffield Council's Working Party on Medical Profiling and Online Medicine.

Miller, R. H., \& Sim, I. (2004). Physicians' use of electronic medical records: barriers and solutions. Health affairs, 23(2), 116-126.

Modi, P. K., Portney, D., Hollenbeck, B. K., \& Ellimoottil, C. (2018). Engaging telehealth to drive value-based urology. Current opinion in urology, 28(4), 342-347.

Moffatt, J., \& Eley, D. (2011). Barriers to the up-take of telemedicine in Australia-a view from providers. Rural and Remote Health Journal, 11(1581), 1-6.

Muthupoltotage, U. P., \& Gardner, L. (2018). Analysing the Relationships Between Digital Literacy and Self-Regulated Learning of Undergraduates-A Preliminary Investigation. In Advances in Information Systems Development (pp. 1-16): Springer.

Nesbitt, T. S., Marcin, J. P., Martha, M., \& Cole, S. L. (2005). Perceptions of local health care quality in 7 rural communities with telemedicine. The Journal of Rural Health, 21(1), 7985.

Nessa, A., Ameen, M., Ullah, S., \& Kwak, K. S. (2008). Applicability of telemedicine in Bangladesh: current status and future prospects. Paper presented at the Convergence and Hybrid Information Technology, 2008. ICCIT'08. Third International Conference on.

Neuman, L. W. (2014). Social research methods: Qualitative and quantitative approaches. Pearson.

Nissen, L., \& Lindhardt, T. (2017). A qualitative study of COPD-patients' experience of a telemedicine intervention. International journal of medical informatics, 107, 11-17.

Oak, M. (2007). A review on barriers to implementing health informatics in developing countries. Journal of Health Informatics in developing countries, 1(1).

Parimbelli, E., Bottalico, B., Losiouk, E., Tomasi, M., Santosuosso, A., Lanzola, G., . . Bellazzi, R. (2018). Trusting telemedicine: a discussion on risks, safety, legal implications and liability of involved stakeholders. International journal of medical informatics, 112, 90-98.

Paul, B. K. (1983). A note on the hierarchy of health facilities in Bangladesh. Social science $\mathcal{E}$ medicine, 17(3), 189-191. 
Peters, D. H., Garg, A., Bloom, G., Walker, D. G., Brieger, W. R., \& Hafizur Rahman, M. (2008). Poverty and access to health care in developing countries. Annals of the New York Academy of Sciences, 1136(1), 161-171.

Ramtohul, I. (2015). The adoption of e-health services: Comprehensive analysis of the adoption setting from the user' s perspective. Health Policy and Technology, 4(3), 286-293.

Rogove, H. J., McArthur, D., Demaerschalk, B. M., \& Vespa, P. M. (2012). Barriers to telemedicine: survey of current users in acute care units. Telemedicine and e-Health, 18(1), $48-53$

Roldán, J. L., \& Sánchez-Franco, M. J. (2012). Variance-based structural equation modeling: guidelines for using partial least squares. Research methodologies, innovations and philosophies in software systems engineering and information systems, 193.

Ross, J., Stevenson, F., Lau, R., \& Murray, E. (2016). Factors that influence the implementation of e-health: a systematic review of systematic reviews (an update). Implementation Science, 11(1), 146.

Sarstedt, M., Wilczynski, P., \& Melewar, T. (2013). Measuring reputation in global marketsA comparison of reputation measures' convergent and criterion validities. Journal of World Business, 48(3), 329-339.

Scott Kruse, C., Karem, P., Shifflett, K., Vegi, L., Ravi, K., \& Brooks, M. (2018). Evaluating barriers to adopting Telemedicine worldwide: A systematic review. Journal of telemedicine and telecare, 24(1), 4-12.

Scott, R. E., \& Mars, M. (2013). Principles and framework for eHealth strategy development. Journal of medical Internet research, 15(7).

Shaarani, I., Taleb, R., \& Antoun, J. (2017). Effect of Computer Use on Physician-Patient Communication Using a Validated Instrument: Patient Perspective. International journal of medical informatics. , 108, 152-157.

Van Dyk, L. (2014). A review of telehealth service implementation frameworks. International journal of environmental research and public health, 11(2), 1279-1298.

van Gemert-Pijnen, J. E., Nijland, N., van Limburg, M., Ossebaard, H. C., Kelders, S. M., Eysenbach, G., \& Seydel, E. R. (2011). A holistic framework to improve the uptake and impact of eHealth technologies. Journal of medical Internet research, 13(4).

Vishwanath, A., \& Scamurra, S. D. (2007). Barriers to the adoption of electronic health records: using concept mapping to develop a comprehensive empirical model. Health Informatics Journal, 13(2), 119-134.

Weiner, M., \& Biondich, P. (2006). The Influence of Information Technology on PatientPhysician Relationships. Journal of general internal medicine, 21(S1).

Weinstein, R. S., Lopez, A. M., Joseph, B. A., Erps, K. A., Holcomb, M., Barker, G. P., \& Krupinski, E. A. (2014). Telemedicine, telehealth, and mobile health applications that work: opportunities and barriers. The American journal of medicine, 127(3), 183-187.

Whittaker, A. A., Aufdenkamp, M., \& Tinley, S. (2009). Barriers and facilitators to electronic documentation in a rural hospital. Journal of Nursing Scholarship, 41(3), 293-300. 
Whitten, P., Holtz, B., Meyer, E., \& Nazione, S. (2009). Telehospice: reasons for slow adoption in home hospice care. Journal of telemedicine and telecare, 15(4), 187-190.

Williams, A. M., Bhatti, U. F., Alam, H. B., \& Nikolian, V. C. (2018). The role of telemedicine in postoperative care. $m$ Health, 4, 11-11. doi:10.21037/mhealth.2018.04.03

Wilson, B. (2010). Using PLS to investigate interaction effects between higher order branding constructs. In Handbook of partial least squares (pp. 621-652): Springer.

Zanaboni, P., \& Wootton, R. (2016). Adoption of routine telemedicine in Norwegian hospitals: progress over 5 years. BMC health services research, 16(1), 496.

Zhang, M., Luo, M., Nie, R., \& Zhang, Y. (2017). Technical attributes, health attribute, consumer attributes and their roles in adoption intention of healthcare wearable technology. International journal of medical informatics, 108, 97-109.

Copyright: @ 2020 Zobair, Sanzogni \& Sandhu. This is an open-access article distributed under the terms of the Creative Commons Attribution-NonCommercial 3.0 Australia License, which permits non-commercial use, distribution, and reproduction in any medium, provided the original author and AJIS are credited.

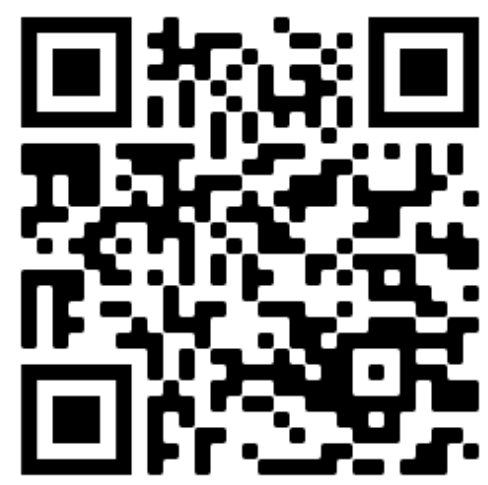

